\title{
Proposta metodológica para o cálculo e análise espacial do IDH intraurbano de Viçosa - MG
}

\author{
Marcos Vinicius Sanches Abreu* \\ Julio Cesar de Oliveira** \\ Viviane Delfino Albuquerque Andrade*** \\ Anderson Donizete Meira****
}

\begin{abstract}
A análise de indicadores socioeconômicos permite uma leitura da realidade capaz de gerar subsídios para o planejamento urbano e a gestão municipal. 0 Índice de Desenvolvimento Humano (IDH) é um importante mensurador do nível de desenvolvimento de um município, por aferir condições de renda, educação e longevidade, mas não é capaz de mostrar as diferenças sociais dentro do município. Neste sentido, para melhor entender a questão socioespacial urbana, a construção de indicadores locais (como o IDH setorizado) torna-se uma importante ferramenta de análise. A metodologia de cálculo deste índice foi adaptada aos dados do Censo 2000 do IBGE, disponibilizados de forma agregada por setores censitários, que constituem a menor unidade de análise territorial composta de dados censitários. De modo a compreender melhor a distribuição e continuidade espacial do IDH, este trabalho propõe a aplicação de técnicas de geoestatística aliadas ao geoprocessamento. Tem-se, portanto, a análise da continuidade espacial do IDH intraurbano, por meio do interpolador geoestatístico de Krigagem Ordinária. Esse processo permite inferir sobre o comportamento espacial do desenvolvimento humano, que possui uma variação contínua no espaço. Ressaltase que se trata de inferências não sobre os valores locais do IDH, mas sim sobre as tendências da variabilidade do indicador. Os resultados se mostraram satisfatórios, visto que é possível fazer a leitura espacial do desenvolvimento humano intraurbano a partir dos dados secundários apresentados pelo Censo.
\end{abstract}

Palavras-chave: Índice de Desenvolvimento Humano (IDH). Setores censitários. Estatística espacial. Krigagem.

\section{Introdução}

Um indicador bastante usado para medir a qualidade de vida é o Índice de Desenvolvimento Humano (IDH), proposto pelo economista paquistanês Mahbub ul Haq. O
IDH é uma espécie de contraponto para o Produto Interno Bruto (PIB) per capita, muito utilizado para aferir o desenvolvimento de determinada região. Enquanto o PIB se preocupa apenas com a dimensão econômica, o IDH engloba, além desta questão, os com-

\footnotetext{
* Engenheiro agrimensor, mestrando em Informações Espaciais pela Universidade Federal de Viçosa.

** Mestre em Sensoriamento Remoto pelo Instituto Nacional de Pesquisas Espaciais - Inpe, professor assistente da Universidade Federal de Viçosa.

${ }_{* \star *}$ Doutora em Economia Aplicada pela Universidade Federal de Viçosa, professora da Faculdade de Viçosa.

${ }^{* * * *}$ Mestre em Engenharia Civil pela Universidade Federal de Viçosa, professor da Faculdade de Viçosa.
} 
ponentes longevidade e educação, sendo que os três níveis possuem o mesmo peso no cômputo do indicador (PNUD, 2008).

$\mathrm{O}$ IDH pode ser calculado em diferentes escalas populacionais, desde países, estados e municípios, até distritos, bairros ou setores num dado município. Contudo, quanto maior a escala populacional, menor é o retrato real do desenvolvimento humano, devido à presença de diferentes territorialidades na área proposta.

Desta forma, a escala de trabalho deve ser compatível com a dinâmica humana de uma região; por exemplo, em uma área intraurbana, o setor censitário se mostra numa escala mais adequada. Segundo o IBGE (2000), o setor censitário é "a menor unidade territorial, com limites físicos identificáveis em campo e com dimensão adequada à operação de pesquisas". Os dados do censo são coletados por setor e disponibilizados de forma agregada pelo mesmo setor.

O Censo Demográfico de 2000 apresenta grande conjunto de variáveis, abrangendo aspectos populacionais, econômicos, condições de higiene, entre outros. A partir deste conjunto de variáveis, é possível calcular o IDH por setor censitário, estabelecendo este como a menor unidade de análise para representar a dinâmica do desenvolvimento humano dentro de uma cidade, como é a proposta deste trabalho.

Deste modo, pretende-se apresentar a espacialização setorizada deste índice dentro da área urbana de um município. Este processo de mapeamento permite analisar a distribuição espacial do IDH, o que imprime uma noção da dinâmica territorial sob o foco do desenvolvimento humano.

Esta apresentação se dá por meio de um mapa coroplético, onde cada setor censitário será representado por um polígono, em que a escala de medida é a intervalar. Assim, cada intervalo de valores do IDH será retratado por uma cor e cada polígono possuirá a cor correspondente ao valor do IDH.

A representação coroplética supõe uma variação abrupta entre valores vizinhos, ou seja, a borda de cada polígono indica uma mudança do padrão espacial de uma variável e, se tratando de variável socioeconô- mica urbana, isso nem sempre é verdade. $O$ IDH é uma variável contínua no espaço, isto é, sua variação se dá de maneira suavizada.

Com a intenção de mostrar essa variação contínua do IDH dentro do município, trabalha-se com superfícies interpoladas por geoestatística. Para Ramos (2002), "este tipo de representação permite uma leitura mais adequada da distribuição contínua da variável". Contudo, não se pode inferir sobre o real comportamento do índice analisando superfícies geradas a partir de dados poligonais. Isso porque o padrão de continuidade apresentado está condicionado ao arranjo espacial dos setores. Deste modo, a superfície geoestatística auxilia apenas na compreensão da dinâmica espacial dos dados censitários, enfatizando áreas de contrastes e concentração dos valores. Para verificar os valores dos dados calculados, deve-se recorrer à representação coroplética.

Assim, o centro deste estudo está na construção de uma metodologia para o cálculo, mapeamento e análise da distribuição do IDH dentro de um município, a partir de dados censitários. Contudo, sabe-se que este não é o indicador ideal, uma vez que trabalha com média aritmética dos valores dos três níveis citados, igualando municípios com características socioeconômicas muito diferentes. Outros indicadores poderiam ser mais fiéis à realidade municipal. Apesar disso, o IDH constitui um indicador referência no território brasileiro, por meio do qual agentes e gestores públicos mascaram realidades internas aos municípios, caso recorrente no município de Viçosa-MG, que será utilizado como base para os estudos aqui apresentados.

\section{Geoprocessamento em aplicações socioeconômicas}

A utilização das ferramentas do geoprocessamento em empresas e instituições públicas e privadas permite que se façam análises geográficas quantitativas sobre a dinâmica do uso e ocupação do solo, ou de dados socioeconômicos, em ambiente digital. Esta análise se dá por meio de métodos e técnicas que objetivam a formulação de modelos de distribuição espacial para 
variáveis regionalizadas, análises do padrão desta distribuição e solução de problemas que envolvam a localização destas variáveis (RAMOS, 2002).

A análise espacial é o conjunto de técnicas matemático-computacionais, que operam sobre um conjunto de dados georreferenciados, de modo a auxiliar o analista no entendimento da dinâmica de determinado fenômeno, dando suporte para a tomada de decisões.

O fenômeno em questão pode estar inserido em diversas áreas do conhecimento, como geologia, agronomia, saúde, sociologia, entre outros (CÂMARA et al., 2002). Assim, a variável espacial pode ser o teor de argila no solo, temperatura, casos de determinado tipo de doença, crimes cometidos, indicadores socioeconômicos, entre outros (ASSUNÇÃO, 2008).

Inúmeros estudos realizados para análise socioeconômica têm difundido as técnicas e os métodos de análise espacial, tornando-se, assim, importantes referências para este trabalho, tais como o Mapa da exclusão/inclusão social da cidade de São Paulo: dinâmica social dos anos 90, coordenado por Sposati (apud GENOVEZ, 2002).

Também Feitosa (2005) procurou desenvolver e avaliar técnicas de mensuração da segregação residencial, buscando captar a dimensão espacial e sua distribuição no Município de São José dos Campos - SP.

Outra importante contribuição para o Município de São José dos Campos foi o trabalho de Genovez (2002). Além de adaptar o método desenvolvido por Sposati à cidade interiorana, a autora buscou o desenvolvimento de técnicas diferenciadas para produção e tratamento dos dados em unidades de análise territorial.

Já Oliveira et al. (2008) descreveram técnicas da cartografia temática e estatística para o mapeamento do IDH por municípios. Um trabalho mais detalhado foi desenvolvido pelo Programa das Nações Unidas para o Desenvolvimento (PNUD) no Brasil, com mapeamento do IDH (entre outros indicadores sociais) em nível de setores censitários para o Município de Recife - PE. Porém, os dados utilizados não foram apenas censitários, mas também de secretarias municipais.

\section{Metodologia}

Área de estudos

O Município de Viçosa está localizado ao norte da Zona da Mata de Minas Gerais, a $229 \mathrm{~km}$ de Belo Horizonte. Situa-se entre as latitudes de 20 을 $41^{\prime} 20^{\prime \prime} \mathrm{S}$ a 20 ㅇ 49' $35^{\prime \prime}$ $\mathrm{S}$ e as longitudes de $42^{\circ}$ 49'36" W a $42^{\circ}$ 54 '27" W, com uma altitude média de 650 metros e área territorial de aproximadamente $300,2 \mathrm{~km}^{2}$.

Segundo o IBGE (2000), o IDH viçosense é de 0,809, considerado alto. $\mathrm{Na}$ dimensão renda, Viçosa apresenta um índice de 0,741 e, no âmbito longevidade, 0,756. O maior destaque é o subíndice educação, com valor de 0,929, o que remete à história educacional da cidade, que sempre se destacou pela aptidão educacional e pelas grandes buscas pela qualidade do ensino no município, desde a década de 1910 (PMV, 2009).

Viçosa é conhecida como "A cidade educadora" por possuir, em sua área urbana, a Universidade Federal de Viçosa (UFV), que consiste em um grande centro acadêmico em nível nacional, destacando-se, principalmente, na área agrária, o Colégio de Aplicação da UFV (Coluni), cujos alunos sempre se destacam nos principais vestibulares do país (UFV, 2009), além de filiais de grandes redes de escolas particulares nos ensinos básico, fundamental e superior.

Conforme descrito anteriormente, os setores censitários são pequenas áreas delimitadas pelo IBGE, destinadas à coleta $\mathrm{e}$ disponibilização de dados censitários. Suas delimitações são baseadas de forma a otimizar a coleta de dados censitários por parte dos recenseadores. Cada setor engloba de 250 a 400 domicílios, abrangendo aproximadamente quatro quadras da malha urbana. A Figura 1 apresenta os setores censitários urbanos da área de estudos.

De acordo com o Censo Demográfico de 2000 (IBGE, 2000), Viçosa possui 75 setores censitários, dos quais foram escoIhidos como área de estudo no presente trabalho os 58 setores da área urbana do distrito sede, além dos seis setores do distrito de Silvestre, justificado pelo fato destes 
FIGURA 1

Setores censitários urbanos

Município de Viçosa - 2000

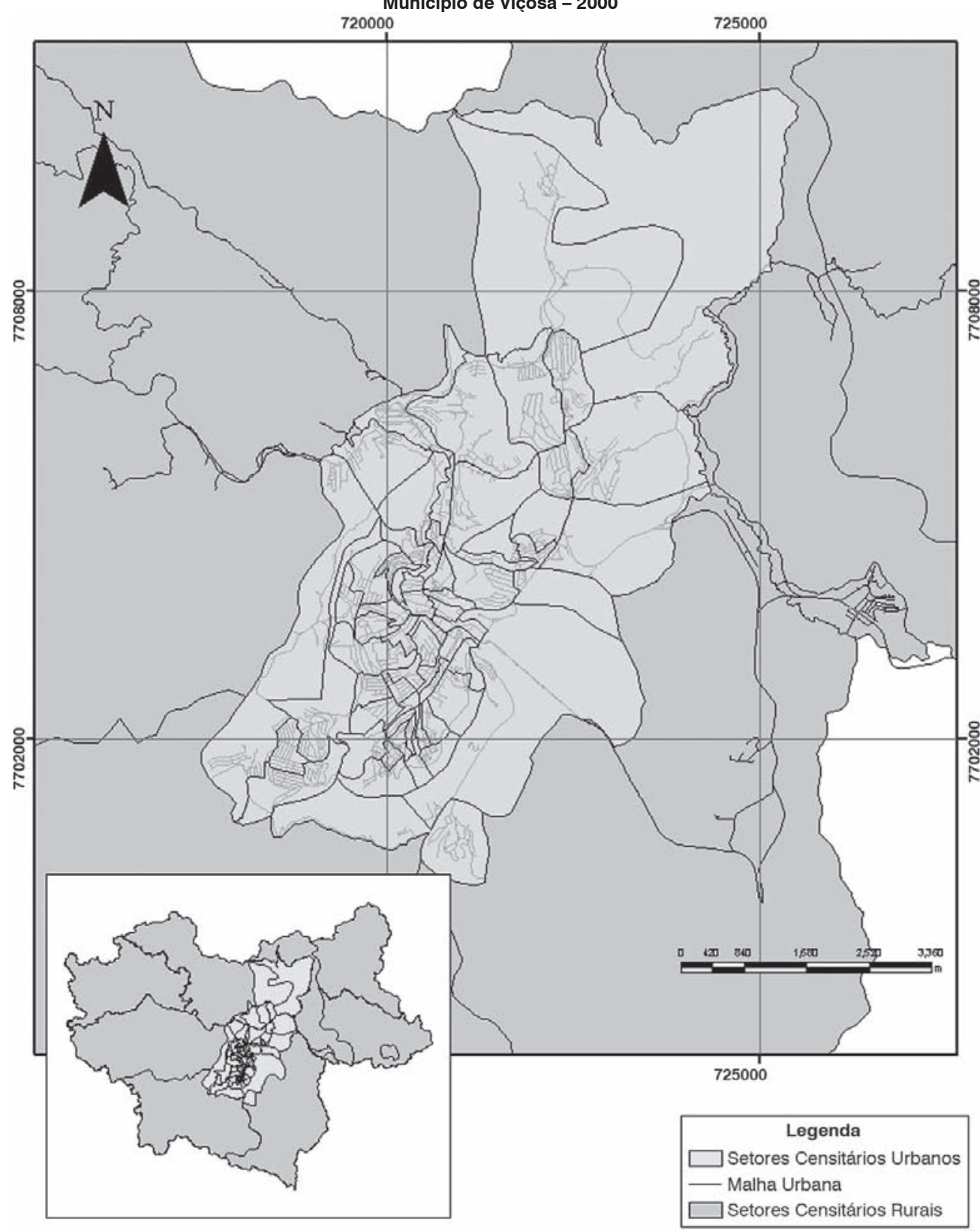

Fonte: Projeto Viçosa Digital.

representarem a extensão da área urbana de Viçosa.

Os outros 11 setores, sendo dois urbanos do distrito de São José do Triunfo, um urbano do distrito de Cachoeira de Santa Cruz e os setores rurais de todos os distritos, ficaram de fora das análises visuais realizadas neste estudo, apesar de terem 
seus valores de IDH calculados. Esta escoIha deve-se às diferenças das condições de vida entre os meios urbano e rural, pois se acredita que usar o mesmo indicador para medir a qualidade de vida na cidade e no campo seja inadequado.

\section{Materiais e equipamentos}

As análises foram realizadas com base na carta geoprocessada dos dados do Censo 2000 agregados por setores censitários de Viçosa, pertencente ao projeto Viçosa Digital - Socioeconomia. Os dados, no formato shapefile ESRI, foram disponibilizados via Núcleo de Inteligência Social da Agência de Desenvolvimento de Viçosa (NIS-Adevi), em parceria com a iPlanus Engenharia e Sistemas e o Serviço Autônomo de Água e Esgoto (SAAE) de Viçosa.

Esta carta contém as 3.216 variáveis geradas com base no levantamento censitário de 2000 , do qual se extraíram as informações necessárias para o cálculo do IDH.

Utilizou-se o ArcGis 9.3 ESRI, empregado para análises visuais, edições tabulares, interpolações por Krigagem Ordinária e geração de layouts. O software Excel 2003 Microsoft foi utilizado para edições tabulares e cálculos de indicadores.

\section{Métodos}

\section{Censo amostral $x$ censo do universo}

Estudou-se uma proposta metodológica para realizar o mapeamento de Índice de Desenvolvimento Humano na escala intraurbana, a partir de dados agregados por setores censitários relativos ao censo do universo de 2000.

Faz-se necessário aqui distinguir o censo do universo do censo amostral, para melhor compreensão da metodologia proposta. O primeiro é aplicado em todas as unidades domiciliares e contém informações básicas dos domicílios e moradores. Já o censo amostral, além dessas informações básicas, levanta dados mais detalhados nos aspectos econômicos e sociais.

A principal diferença entre os dois é que, em municípios com mais de $15 \mathrm{mil}$ habitantes, o censo amostral é aplicado em um a cada dez domicílios recenseados com o questionário universal. Portanto, considerando um setor com 400 domicílios, o censo amostral cobriria apenas 40 deles, o que poderia questionar o nível de representatividade para o setor. Logo, dados e informações amostrais são disponibilizados apenas por município.

Como o objetivo deste trabalho é mostrar as diferenças intraurbanas do desenvolvimento humano, as variáveis do censo amostral não se mostram suficientes para tal análise. Deste modo, somente variáveis do censo do universo foram utilizadas.

\section{Escolha das variáveis censitárias e geração do IDH}

$\mathrm{O}$ IDH foi criado, inicialmente, para medir o desenvolvimento humano em países, aferindo condições de renda, educação e longevidade (PNUD, 2003). Com base em sua importância e aceitação na sociedade como indicador da qualidade de vida, ele foi trazido para a realidade municipal (OLIVEIRA, 2008).

Os três subíndices medidos são utilizados com pesos iguais no cálculo do IDH, que é obtido por meio da média aritmética dos subíndices IDH-Renda, IDH-Longevidade e IDH-Educação.

O PNUD, em parceria com o IBGE, realiza o mapeamento do IDH por municípios. Para tal, a metodologia utilizada em países foi modificada com a justificativa de buscar maior adequação para avaliar núcleos menores, como municípios ou regiões. A principal alteração ocorreu na dimensão educacional (PNUD, 2003).

Neste trabalho, adotou-se postura semelhante para o cálculo do índice intraurbano. Isto deve-se à limitação dos dados utilizados, já que algumas informações necessárias para calcular o indicador constam apenas no censo amostral.

\section{Dimensão renda}

Em nível nacional, utiliza-se o PIB per capita como medida do aspecto econômico para o cômputo do IDH. Já em escala 
municipal, este parâmetro é substituído pela renda per capita. Assim, no presente estudo, utilizou-se este mesmo critério para os setores censitários, sendo que, em cada setor, o rendimento nominal mensal total foi dividido pela população total, obtendo-se a renda setorizada per capita.

A população total é aquela residente nos domicílios contidos em cada setor, classificados em particulares permanentes (casas, apartamentos, etc.), particulares improvisados (casas e prédios em construção, barracas, vagões de trem, etc.) e coletivos (hotéis, pensões, asilos, hospitais, etc.) (IBGE, 2000).

Mencionam-se duas limitações da aplicação desta metodologia: a primeira é que a única variável indicativa do rendimento nominal mensal por setor é aquela correspondente às pessoas responsáveis por domicílios, o que não corresponde, portanto, à renda total do setor, uma vez que exclui aquela dos demais moradores do setor; a segunda refere-se ao fato de que, nos dados do IBGE, consta apenas a renda dos chefes de domicílios particulares permanentes, ficando excluída aquela proveniente dos chefes de famílias residentes nos outros tipos de domicílios.

Porém, o número de pessoas residentes nestes outros tipos de domicílios é pequeno em relação ao de pessoas moradoras nos particulares permanentes. Há apenas uma ressalva na região norte de Viçosa (bairro Novo Silvestre), onde metade da população residia em domicílios considerados coletivos.

Acredita-se que a diferença entre residentes em domicílios particulares permanentes e residentes totais, em cada setor, não implique grandes distorções no resultado deste trabalho, pois seria mínimo o incremento na renda total de cada setor se considerados os responsáveis por outros tipos de domicílios, já que estes estão em menor número.

Segundo o PNUD (2003), na metodologia do IDH-Municipal, utilizam-se os valores tabelados de $\mathrm{R} \$ 1.560,17$ e $\mathrm{R} \$ 3,90$ para transformar a renda municipal per capita em um índice. Estes valores referem-se, respectivamente, à Paridade do Poder de
Compra máxima (US\$ PPC 40.000,00) e mínima (US\$ PPC 100,00), adotados nos relatórios internacionais, convertidos em reais para o dia 1 de agosto de 2000 pelo próprio PNUD.

De modo a representar melhor o fato de que pequenos acréscimos na renda dos mais pobres são mais significativos do que na renda dos mais ricos, o PNUD emprega o uso da função logarítmica na renda per capita de cada setor censitário e nos valores máximo e mínimo de referência.

Por fim, o valor do IDH-Renda é calculado da seguinte forma:

$I D H-R=\left(\log _{r p c}-\log _{r m i}\right) /\left(\log _{r m a}-\log _{r m i}\right)(1)$ onde:

$\log _{r p c}$ é o logaritmo da renda per capita do setor censitário;

Log $_{\text {rmi }}$ é o logaritmo da referência mínima;

$\log _{r m a}$ é o logaritmo da referência máxima.

As variáveis utilizadas neste processo foram a V0623 (total do rendimento nominal mensal das pessoas responsáveis por domicílios particulares permanentes) e a V0237 (moradores ou população residente no setor). Portanto, dividindo-se V0623 por V0237, tem-se o valor da renda setorizada per capita.

\section{Dimensão longevidade}

O indicador de longevidade, que sintetiza as condições de salubridade e de saúde de uma região, mede a quantidade de anos que uma pessoa deve viver, mantidas constantes as condições de mortalidade no local (PNUD, 2003).

Tanto para o IDH-Nacional quanto para o IDH-Municipal, a dimensão longevidade é calculada a partir dos dados relativos à esperança de vida ao nascer, que, por sua vez, é baseada em taxas de mortalidade. Contudo, informações desse tipo são obtidas apenas no censo amostral, o que impede a utilização da mesma metodologia neste trabalho, visto que não há dados deste tipo por setores censitários.

Para resolver este problema, assumiu-se que a dimensão longevidade do IDH-Municipal constitui a média do indicador em todos os setores. Dada essa premissa, buscou-se encontrar a expectativa de vida 
populacional viçosense, aplicando-se o valor de 0,756 , que corresponde ao IDH-Longevidade municipal (PNUD, 2009), na inversa da equação 2 , que define o IDH-Longevidade em função da expectativa de vida (PNUD, 2003):

$I D H-L=(E V-25) /(85-25)$

onde:

$E V$ é a expectativa de vida (em anos);

25 e 85 correspondem às idades mínima e máxima utilizadas pelo PNUD, respectivamente.

Constatou-se que a expectativa de vida viçosense é de aproximadamente 70 anos. Analisando a distribuição acumulada de pessoas por idade no município (obtida no Excel 2003 a partir da soma acumulada do número de pessoas em cada idade), verificou-se que $96,8 \%$ da população possui entre 0 e 70 anos. Com a condição admitida anteriormente de que a longevidade municipal constitui a média setorial, cada setor possui $96,8 \%$ de sua população abaixo da idade referente à sua expectativa de vida.

O passo seguinte foi multiplicar o número de pessoas residentes em cada setor por 0,968, o que permite encontrar o número de pessoas com idade abaixo da correspondente à expectativa de vida de cada setor. Porém, esse número não é do tipo inteiro. Para transformá-lo em inteiro, criou-se a distribuição acumulada de pessoas por idade para cada setor e, a partir dela, utilizando-se a função $P R O C$ do Excel 2003, obteve-se o número de pessoas imediatamente abaixo do número encontrado anteriormente, em cada setor.

Desta forma, foi determinado para cada setor um valor inteiro equivalente ao número acumulado de pessoas imediatamente inferior ao valor real correspondente a $96,8 \%$ da população total do setor.

A partir do número de pessoas abaixo da idade assumida como a expectativa de vida e da distribuição acumulada de pessoas por idade, determinou-se a idade correspondente à expectativa de vida de cada setor.

As variáveis utilizadas no cálculo da longevidade foram as V1347 a V1447, referentes ao número de pessoas em cada idade por setor censitário.

\section{Dimensão educação}

O IDH-Educação trabalha basicamente com taxas de alfabetização e de matrículas. No índice municipal, a taxa de alfabetização mede o número de pessoas com mais de 15 anos alfabetizadas. Este critério é utilizado porque, segundo o calendário do MEC, uma pessoa já deve estar alfabetizada ao fim do ensino fundamental, isto é, com 14 anos (PNUD, 2003).

Já a taxa de matrícula mede o acesso ao ensino por parte da população. No âmbito nacional, divide-se o número de matriculados nos níveis fundamental, médio e superior pelo número de pessoas entre 7 e 22 anos. Este intervalo de idade é a faixa etária da população que deveria estar envolvida com o aprendizado, de acordo com o estabelecido pelo MEC (PNUD, 2003).

Para municípios, a taxa de matrícula foi substituída pela frequência à sala de aula, pois uma pessoa pode estar matriculada em uma cidade e morar em outra, distorcendo as taxas municipais de matrículas. Assim, mede-se a parcela da população que vai à escola em relação à população em idade escolar (PNUD, 2003). Contudo, informações de frequência escolar são obtidas apenas no censo amostral.

Devido à limitação encontrada, semeIhante ao caso de longevidade, aqui se propõe substituir a taxa de frequência à sala de aula pela média normalizada de anos de estudos dos chefes de família e a taxa de alfabetização de pessoas entre 7 e 14 anos de idade.

A média normalizada é justificada pelo fato de que pessoas são influenciadas, direta ou indiretamente, pelos seus responsáveis, pois se pressupõe que há maior probabilidade de um indivíduo seguir seus estudos até o ensino superior, quando seus responsáveis atingiram esse nível. O contrário também é válido.

Segundo o PNUD (2003), consta no calendário do MEC que o tempo de estudos até se concluir o ensino superior é de 15 anos (dos 7 aos 22 anos de idade). Para a conversão das médias de anos de estudos dos chefes de família em valores entre 0 e 1, os valores disponibilizados no censo, 
referentes aos anos de estudos dos chefes de família, foram divididos por 15. Este procedimento fornece a média normalizada de anos de estudos dos chefes de família. Ressalta-se que, caso um setor apresente média superior a 15 anos, o mesmo será representado pelo valor 1 , por se considerar que já atingiu a cota do MEC em relação ao número de anos necessários para concluir o nível superior.

Por sua vez, a utilização da taxa de alfabetização de pessoas entre 7 e 14 anos deve-se ao fato de considerar que uma pessoa alfabetizada nessa faixa etária esteve matriculada no ensino fundamental há pelo menos sete anos. Essa hipótese, que está apoiada no calendário do MEC, como citado anteriormente, remete à ideia de matrícula recente em nível básico de educação.

Assim, o IDH-Educação setorizado é calculado, no presente trabalho, pela média ponderada entre as três variáveis: taxa de alfabetizados acima de 15 anos (como proposto na metodologia original); média normalizada de anos de estudos dos chefes de família; e taxa de alfabetizados entre 7 e 14 anos (sendo que estas duas últimas variáveis substituem a frequência escolar). Os pesos para a média são 1,1 e 2, respectivamente, contrariando a metodologia proposta no IDH-Municipal, que dá peso 2 à taxa de alfabetização de pessoas acima de 15 anos e 1 para a frequência em sala de aula.

Essa diferença na ponderação entre a metodologia usual e a proposta deve-se ao entendimento dos autores de que a alfabetização entre 7 e 14 anos engloba características locais ao índice, como acessibilidade à educação e qualidade do ensino local. Alguns setores censitários podem não possuir proximidades a escolas, ou até mesmo podem ter escolas com condições precárias de ensino.

As variáveis utilizadas neste estudo foram as V1347 a V1447, que contêm informações sobre a idade da população, as V2248 a V2325, que indicam o número de pessoas alfabetizadas por idade, a V0599 (pessoas responsáveis por domicílios particulares permanentes com número de anos de estudo determinado) e a V0601 (total de anos de estudo das pessoas responsáveis por domicílios particulares permanentes). Os cálculos foram realizados no Excel 2003, a partir de funções simples de adição e multiplicação.

\section{Cálculo e espacialização do IDH}

Com os subíndices renda, longevidade e educação calculados, a etapa subsequente foi calcular o IDH propriamente dito. Isso foi feito a partir da média simples entre os três subíndices, ou seja, para cada setor censitário realizou uma soma dos subíndices e dividiu-se por 3

Feito isso, procedeu-se à espacialização dos mesmos através do software ArcGis 9.3 e da representação espacial dos setores censitários de Viçosa-MG. Todas as tabelas possuem como campo-chave o código de cada setor censitário, de forma a relacionar as informações espaciais com as respectivas informações descritivas de cada setor.

\section{Utilização da geoestatística para compreensão da continuidade espacial de variáveis socioeconômicas}

Segundo Ramos (2002), a interpolação de dados socioeconômicos surge como uma alternativa para representar os mesmos, pois esta permite uma análise mais adequada da variação contínua das condições de uma região, o que não é feito analisando-se indicadores condicionados à unidade de áreas.

Jakob (2002) afirma que a interpolação minimiza os contrastes entre os polígonos, evitando o que ele chama de "colcha de retalhos". Porém, é necessário tomar cuidados ao se afirmar isso, uma vez que a interpolação de dados socioeconômicos objetiva mostrar a variação dos mesmos no espaço, e não suavizar seus contrastes. Não se pode esquecer que dados e indicadores desta espécie estão condicionados à forma como foram coletados, ou seja, os limites dos polígonos definem seus valores.

Portanto, interpolar indicadores provenientes de dados agregados em áreas não significa inibir o contraste entre duas áreas, mas sim inferir apenas sobre a variação destes indicadores no espaço, que está 
condicionada ao arranjo espacial dos setores. Ressalta-se que, com a interpolação, perdem-se os valores reais de cada área, não sendo, por conseguinte, ideal para se obter o valor do indicador numa determinada área.

Existem duas categorias de interpoladores de amostras espaçadas: os determinísticos e os estocásticos. Os primeiros consideram apenas as configurações espaciais das amostras, não se preocupando com a variabilidade das mesmas. Encontram-se aqui os interpoladores do inverso da distância, vizinhos mais próximos, etc., como destacam Ramos (2002) e Burrough e McDonell (1998).

Em contrapartida, na segunda classe, o processo de interpolação se baseia na variabilidade espacial das amostras pontuais, consideradas variáveis regionalizadas, cuja teoria foi formulada por Matheron em 1963 (SCHULER, 2007). Segundo Vicente (2004), a variável regionalizada possui como características a localização, a anisotropia (variações diferentes em diferentes direções, as quais dependem das características do fenômeno) e a continuidade (baseada na primeira lei da geografia, que será descrita mais adiante).

Em geoestatística, segundo Felgueiras (1999), "os valores dos atributos são representados como variáveis ou campos aleatórios". O autor ainda afirma que o método de interpolação conhecido como Krigagem permite inferir valores de um atributo espacial a partir de amostras pontuais para qualquer região.

Burrough e McDonnell (1998) acrescentam que em Krigagem o atributo é conhecido como variável regionalizada, e sua aplicação também é válida para a distribuição de variação contínua de indicadores demográficos. A Krigagem considera a continuidade e a distância entre dois pontos, podendo ser um amostral e um não-amostral (SANTOS, 2008).

Ramos (2002) apresenta dois métodos de interpolação por Krigagem: a Krigagem Ordinária e a Krigagem Ordinária por Indicação. Para Felgueiras (1999), a Krigagem Ordinária possui um algoritmo mais robusto do que outros estimadores por Krigagem, pois trabalha com médias ou tendências estimadas localmente, em contrapartida aos outros, que preestabelecem uma média estacionária.

A Krigagem é um método de interpolação abalizado em ponderações dos dados amostrais. Essa ponderação é baseada na distância que separa duas amostras e na variância entre elas. Por sua vez, a análise da variância entre as amostras é fundamentada no conceito da continuidade espacial, que é demonstrada pela modelagem do semivariograma.

Esta característica está centrada na Primeira Lei da Geografia de Tobler, segundo a qual as coisas tendem a se parecer, porém, as coisas mais próximas entre si se parecem mais do que as coisas mais distantes (JAKOB, 2002; WONG, 1995; ISAAKS; SRIVASTAVA, 1989). A avaliação da continuidade espacial se dá pelos conceitos de regressão linear para analisar a dependência espacial entre duas variáveis (VICENTE, 2004).

Em geoestatística, a maneira mais apropriada para se obterem informações sobre a dependência espacial é a utilização da função semivariograma $(\gamma)$, mostrada na Figura 2. Vicente (2004) e Isaaks e Srivastava (1989) explicam e detalham a origem e os princípios desta função.

Como o semivariograma descreve a continuidade espacial, que se baseia na Primeira Lei de Tobler, a função semivariograma demonstra que as diferenças entre amostras separadas por um vetor $\vec{h}$ são menores quando $\vec{h}$ também é menor, ou seja, quanto menor o valor da função, mais provável é a continuidade espacial da variável em estudo.

Como pode ser visto na Figura 2, a função semivariograma possui quatro parâmetros, a saber: patamar (nível onde o variograma se estabiliza e considera-se que não haja mais dependência espacial entre as observações); alcance (distância $h$ a partir da qual não há dependência espacial); efeito pepita (apresenta a descontinuidade do semivariograma para distâncias inferiores à menor distância de interesse entre as amostras); e contribuição (o quanto de informação os pares de pontos estão fornecendo). 
FIGURA 2

Exemplo de semivariograma experimental

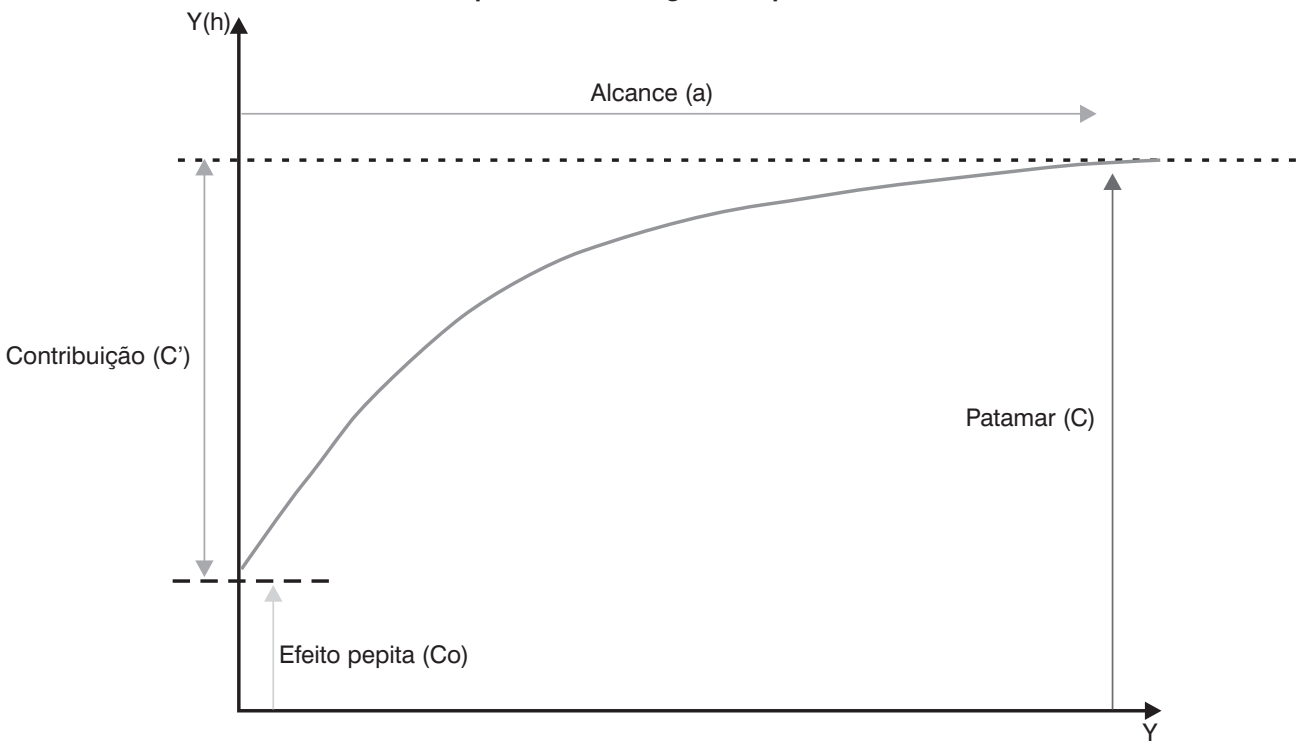

Fonte: Vicente (2004)

O semivariograma é construído a partir de um conjunto de valores obtidos por uma equação que relaciona a variância entre as amostras e a distância que as separa, conforme descrito em Vicente (2004). O autor chama este gráfico de semivariograma experimental, acrescentando que deve ser ajustado um modelo a ele, de modo a representar a tendência da função semivariograma em relação a certa distância. O gráfico é plotado a partir da equação 3:

$\gamma(h)=\sum\left(v_{j}-v_{i}\right)^{2} / 2 * N(h)$

onde:

$\gamma(h)$ é o semivariograma;

$N(h)$ é o número de pares de pontos que estão a uma determinada distância $h$; $v_{i}$ e $v_{\mathrm{j}}$ são amostras nas localizações $i$ e $j$.

Este modelo é ajustado de maneira interativa com o pesquisador, com base nos diferentes semivariogramas teóricos, que, por sua vez, devem representar de maneira satisfatória a tendência mostrada pelo semivariograma experimental, permitindo que as estimativas por Krigagem apresentem variâncias mínimas (SCHULER, 2007).

O modelo teórico é utilizado porque, na maioria das vezes, torna-se impossível obter os parâmetros necessários para a modelagem da dependência espacial das amostras a partir do semivariograma experimental (SANTOS, 2008). Camargo (1997) apresenta, de forma detalhada, os principais modelos teóricos (esférico, exponencial e gaussiano), citando também a modelagem aninhada (ou complexa) e da anisotropia (distribuição mais intensa numa direção e menos em outra).

Definido e ajustado o modelo teórico, parte-se para a determinação dos pesos atribuídos às amostras, utilizando a modelagem do semivariograma, segundo o método escolhido de interpolação estabelecido pela Krigagem Ordinária.

Camargo (1997) mostra que, para obtenção de um estimador não tendencioso e sem a necessidade de conhecimento prévio da média do atributo em estudo (características da interpolação por Krigagem Ordinária), basta que o somatório dos pesos seja igual a 1. Assim, o estimador de Krigagem Ordinária é dado por:

$Z^{*}(x 0)=\sum \lambda_{i} * Z(x i)$

Sendo:

$Z^{*}(x 0)$ o valor do atributo a ser estimado na posição $x 0$; 
$\sum \lambda_{i}$ o somatório dos pesos, com $i$ variando de 1 a $n$, sendo $n$ o número de valores amostrados;

Z (xi) o valor do atributo a em cada amostra posicionada em $x i$.

Ao minimizar a variância do erro sob a condição $\sum \lambda_{i}=1$ (CAMARGO, 1997), os pesos passam a ser obtidos a partir de um sistema de equações de Krigagem Ordinária e podem ser escritos sob notação matricial como descreve a equação 5 :

$K * \lambda=k$ ou $\lambda=K^{-1} * k$,

onde:

$K$ é a matriz de covariância entre as amostras;

$k$ é a matriz de covariância entre as amostras e o ponto a ser estimado;

$\lambda$ é o vetor dos pesos.

As covariâncias são obtidas em função das distâncias entre os pontos amostrais e o ponto a ser estimado, e com base na modelagem do semivariograma teórico ajustado sobre o semivariograma experimental. A função do modelo teórico do semivariograma varia de acordo com o próprio modelo e se apresenta da seguinte forma:

$\gamma(h)=f\left(C_{0}, C_{1}, a, h\right)$

sendo:

$C_{0}$ o efeito pepita;

$C_{1}$ a contribuição;

$a$ o alcance;

$h$ o vetor distância entre dois pontos.

Aplica-se a equação do modelo teórico escolhido em cada par amostral ou não amostral, sendo a distância entre eles a variável independente, obtendo-se assim a semivariância entre o par.

Cada semivariância é inserida na matriz correspondente ( $K$ ou $k$ ). A partir da equação 6 , obtêm-se os pesos entre as amostras e cada ponto não amostral. O passo seguinte é obter o valor do atributo em um ponto não amostral aplicando-se a equação 5 .

\section{Análise da continuidade espacial do IDH setorizado}

O conceito de Krigagem foi introduzido por Daniel G. Krige, que foi o primeiro a utilizar o conceito de médias móveis para evitar a superestimação sistemática em reservas de mineração (VICENTE, 2004). A partir dos estudos de Krige, Matheron desenvolveu a teoria das variáveis regionalizadas, cujas características foram citadas anteriormente. Para que sejam interpolados por Krigagem Ordinária, os indicadores analisados neste trabalho precisam ser considerados variáveis regionalizadas.

Existe a condição de localização geográfica inserida às variáveis estudadas neste trabalho, uma vez que o mesmo objetiva mostrar a variação do IDH e seus subíndices entre as suas diversas localizações.

Nota-se também a presença da continuidade espacial, embora esta seja condicionada à distribuição das áreas residenciais, uma vez que os dados originários do IDH são provenientes de levantamentos domiciliares. Deste modo, condições socioeconômicas territoriais obtidas em campo podem apresentar descontinuidade espacial em virtude dos vazios urbanos, e esta descontinuidade deve ser considerada quando representada por superfícies contínuas (RAMOS, 2002).

A anisotropia também pode ser observada, já que, no meio urbano, existem regiões mais desenvolvidas do que outras, caracterizadas por diferenças na presença de infraestrutura e/ou concentração de serviços urbanos, por exemplo. Portanto, o índice pode variar de maneira diferente em direções distintas.

A seguir, apresentam-se os experimentos realizados para a geração de superfícies contínuas, por Krigagem Ordinária, que representem a variabilidade do desenvolvimento humano na área urbana do Município de Viçosa - MG. Antes, porém, vale lembrar que a geoestatística trabalha com valores pontuais.

No presente trabalho, os pontos amostrais corresponderam aos centroides dos setores censitários, uma vez que se admite uma distribuição de densidade constante por todo o interior da área. Sob a Falácia Ecológica, assume-se que cada indivíduo interno a um polígono possui as características inerentes a este polígono. Entretanto, ressalta-se que os dados estão condicionados às interferências dos problemas de unidades de área modificáveis (RAMOS, 2002) e à dificuldade de se encontrar o centro de massa do atributo no polígono. 
Além disso, nem todo o centroide de um polígono está dentro deste mesmo polígono. Porém, como aqui se pretende mostrar apenas a continuidade da variação do IDH e não a predição do valor do IDH em todos os pontos da superfície municipal, acredita-se que a posição relativa dos centroides não distorça completamente os resultados.

Esta conversão de polígonos para pontos é feita automaticamente no software ArcGis 9.3, o qual foi utilizado para a realização deste procedimento. A extensão empregada no software foi a Geostatistical Analyst.

Apesar de o escopo do trabalho ser a representação do IDH no espaço urbano, escolheu-se realizar a interpolação por geoestatística de toda a área municipal, devido à necessidade de se considerar a vizinhança dos setores censitários situados nos limites da zona urbana. Esta escolha baseia-se na primeira lei da geografia, citada anteriormente, pois estas regiões vizinhas, mesmo que rurais, exercem influências nos setores extremos do perímetro urbano.

Obviamente, deve-se levar em conta que os valores apresentados pelos indicadores no meio rural foram retirados da análise por não serem considerados suficientes para indicar o nível de desenvolvimento humano nos setores rurais. Por outro lado, não se pode dizer que os limites dos setores urbanos impedem a influência de regiões próximas. De modo a representar somente a área urbana do município, criou-se uma máscara com o limite urbano.

\section{Modelagem da continuidade espacial do indicador}

O primeiro passo foi a modelagem dos semivariogramas do IDH. Após os valores de semivariância serem plotados no semivario- grama, verificou-se a presença da anisotropia através da superfície de semivariograma. O ArcGis auxilia na modelagem anisotrópica, mostrando as direções de maior e menor continuidade espacial e preestabelecendo um semivariograma experimental para cada uma das diversas direções.

Os procedimentos de ajuste dos semivariogramas experimentais foram feitos de maneira interativa com o software. Os parâmetros fundamentais do semivariograma, como patamar, efeito pepita e alcance, permaneceram da mesma maneira como preestabelecidos pelo algoritmo. Porém, algumas modificações foram feitas nos números de lags, nas distâncias entre cada lag e nas larguras do bandwidth. Estes parâmetros indicam a janela de tolerância utilizada na variografia exploratória, como cita Schuler (2007). Após vários testes, verificou-se que o melhor tipo de semivariograma experimental para cada indicador foi o Gaussiano.

As análises dos erros de predição mostram que os modelos ajustados foram satisfatórios. Isto é apurado nas retas das respectivas funções de regressão, que possuíram interceptos sempre menores que a unidade. Os valores apresentados em suas médias de erros de estimação, bem como seus valores quadráticos médios (RMS), também foram considerados bons (Tabela 1).

\section{Resultados}

Os resultados são apresentados por setores censitários em forma de mapas temáticos coropléticos. Os tons mais claros indicam valores de IDH baixos, enquanto os mais escuros significam valores maiores de IDH.

TABELA 1

Parâmetros dos erros de validação

\begin{tabular}{ll}
\hline Parâmetros dos erros de estimação & \multicolumn{1}{c}{ IDH } \\
\hline Função de regressão & $0,743 \cdot x+0,190$ \\
Média & 0,0009101 \\
RMS & 0,04883 \\
Média padronizada & 0,006194 \\
RMS padronizado & 0,8575 \\
\hline
\end{tabular}

Fonte: Elaboração dos autores. 
Como se pode observar na Figura 3, houve grande concentração de alto valor do Índice de Desenvolvimento Humano na região central da área urbana, pois a Rua Milton Bandeira, localizada na região central do município, apresenta IDH de 0,94. Da

FIGURA 3

Setorização do IDH intraurbano

Município de Viçosa - 2000

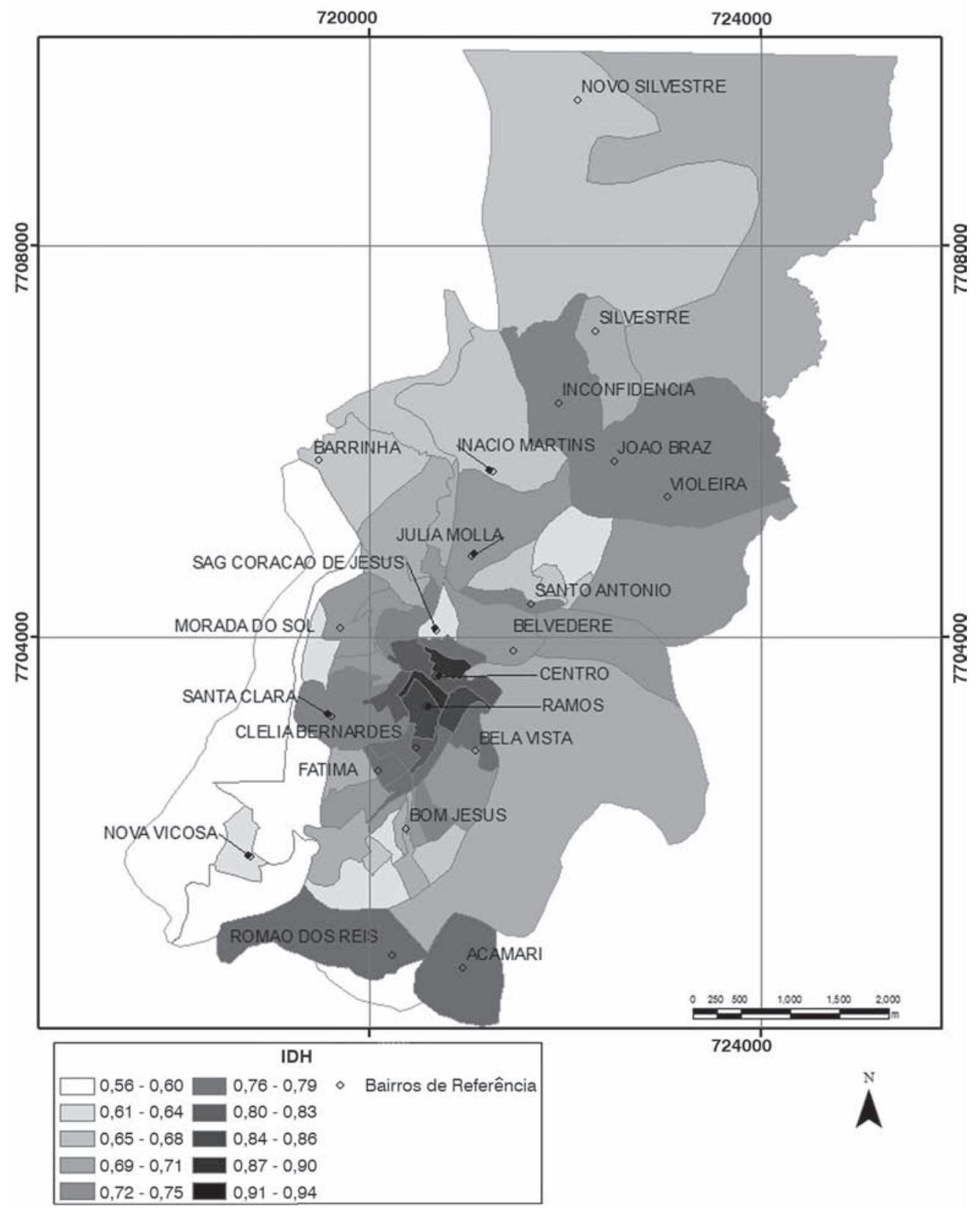

Fonte: IBGE. Censo Demográfico 2000. Elaboração dos autores. 
mesma forma, a área que compreende os Bairros de Ramos e Clélia Bernardes registra valor acima de 0,87.

Também se verifica, neste mapa, que a periferia de Viçosa apresenta valores medianos para o desenvolvimento humano, com uma leve tendência a valores altos na região norte. Por outro lado, como destaques negativos, estão o alto do Bairro Santo Antônio (Morro da Coruja), o Bairro Sagrado Coração de Jesus (Rebenta Rabicho) e o Bairro de Nova Viçosa, com valores de 0,63, 0,63 e 0,57 , respectivamente.

$\mathrm{Na}$ Figura 4, a representação do IDH intraurbano se dá de outra maneira, não estando ligada ao setor censitário, mas sim à menor célula espacial de sua imagem (pixel), que neste mapa representa uma área de $5 \mathrm{~m}$ por $5 \mathrm{~m}$. Este tipo de representação foi intitulado de continuidade espacial do IDH.

Percebe-se, neste mapa, a ocorrência de três regiões escuras ao longo da cidade, localizadas nas partes norte, central e sul do município. Estas áreas correspondem, respectivamente, aos bairros João Brás, Centro e Acamari, podendo ser denominadas de manchas do desenvolvimento.

Por outro lado, também existem três áreas claras, que podem ser chamadas de manchas do subdesenvolvimento, constituídas pelas regiões da Barrinha e Vau Açu, Alto Santo Antônio (Morro da Coruja) e Nova Viçosa. A mancha no Morro da Coruja se destaca por estar entre duas manchas de desenvolvimento. Por sua vez, a mancha de Nova Viçosa é a mais clara entre todas, mostrando baixo nível de desenvolvimento.

A mancha de desenvolvimento presente na região do Acamari está centrada exatamente no centro do Bairro Romão dos Reis. Isto deve-se ao fato de o centroide do setor censitário estar neste bairro. Por conhecimento empírico, sabe-se que o Romão dos Reis é uma comunidade carente, em situação muito oposta àquela encontrada no Acamari.

Este fato também pode ser percebido em Belvedere e Recanto da Serra, que se encontram nos mesmos setores censitários de Santo Antônio e da Violeira, respectivamente. Portanto, aqui se percebem limitações dos dados utilizados, ou seja, valores condicionados aos limites dos setores censitários e posicionamento dos centroides.

\section{Conclusão}

Como fonte de informações seguras sobre a dinâmica intraurbana, percebe-se a clara contribuição da aplicação da Estatística Espacial aliada ao Geoprocessamento. A união destas ferramentas permite entender o comportamento de variáveis socioeconômicas, contribuindo para uma leitura eficaz da realidade urbana e auxiliando de forma mais eficiente nos processos de estudos da dinâmica populacional de uma cidade.

$\mathrm{O} I \mathrm{IDH}$ foi escolhido neste trabalho devido à sua importância para obtenção de recursos federais para implantação de políticas públicas municipais. Espera-se, portanto, que os resultados aqui apresentados contribuam para a gestão municipal de Viçosa - MG, mostrando, do modo mais fiel possível, a realidade do desenvolvimento humano na cidade.

A metodologia empregada mostrou-se satisfatória, uma vez que foi capaz de representar as diferenças intraurbanas do ponto de vista da qualidade de vida da população. Sabe-se que a realidade da periferia viçosense encontra-se em situações de extrema pobreza. No entanto, o conhecimento empírico é subjetivo para validar o modelo proposto. Neste sentido, sugerem-se estudos estatísticos que mostrem a veracidade da metodologia proposta.

Obviamente, os estudos realizados aqui podem ser aplicados em mais indicadores socioeconômicos, sejam censitários ou não, bem como agregados por área ou pontuais, como, por exemplo, as ocorrências de doenças ou crimes. O emprego da Estatística Espacial torna a análise espacial de dados geográficos mais rica, permitindo deduções qualitativas ao processo de análise.

Com relação à geração de superfícies contínuas, a Krigagem se mostra o processo ideal de interpolação de dados socioeconômicos, pois leva em conta a variabilidade dos mesmos. Interpoladores determinísticos considerariam que as variações entre as amostras seriam constantes. 
FIGURA 4

Continuidade espacial do IDH intraurbano Município de Viçosa - 2000

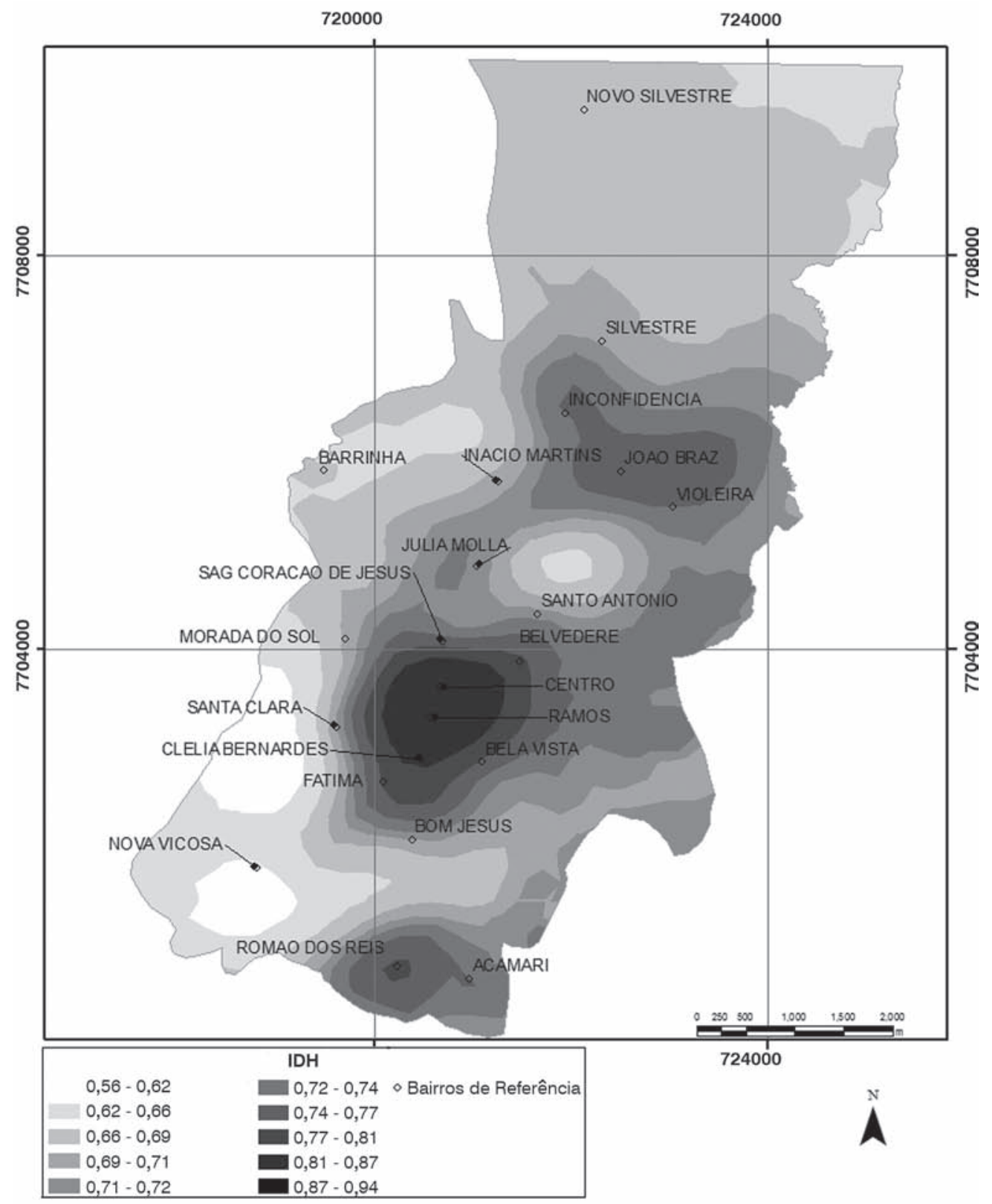

Fonte: IBGE. Censo Demográfico 2000. Elaboração dos autores.

A análise geoestatística dos indicadores socioeconômicos permite entender melhor o comportamento dos mesmos na malha urbana, já que, por ela, são eliminadas as fronteiras dos setores. Entretanto, não se pode afirmar que os valores apre- 
sentados nas superfícies correspondem aos valores exatos de cada região urbana, pois, se os setores censitários estivessem arranjados de outra forma, os valores do índice para cada região poderiam ser bem diferentes daqueles apresentados neste trabalho.

O presente estudo focou-se na formulação de uma metodologia para cálculo e aná-

\section{Referências}

ASSUNÇÃO, R. M. Curso de Estatística Espacial. Disponível em: <http://www.est.ufmg. $\mathrm{br} /$ assuncao/>. Acesso em: out. 2008.

BURROUGH, P. A.; MCDONNELL, R. A. Principles of Geographical Information Systems. Oxford: Oxford University Press, 1998.

CÂMARA, G.; CARVALHO, M. S.; CRUZ, O. G.; CORRÊA, V. Análise espacial de áreas. Brasília: Embrapa, 2004. Disponível em: <http://www.dpi.inpe.br/gilberto/livro/analise/ cap5-areas.pdf/> . Acesso em: set. 2008.

FEITOSA, F. F. Índices espaciais para mensurar a segregação residencial: o caso de São José dos Campos (SP). Dissertação (Mestrado em Sensoriamento Remoto). São José dos Campos: Instituto Nacional de Pesquisas Espaciais, 2005.

FELGUEIRAS, C. A. Modelagem ambiental com tratamento de incertezas em Sistemas de Informações Geográficas: paradigma geoestatístico por indicação. Tese (Doutorado em Computação Aplicada). São José dos Campos: Instituto Nacional de Pesquisas Espaciais, 1999.

GENOVEZ, P. Território e desigualdades: análise espacial intraurbana no estudo da dinâmica de exclusão/inclusão social no espaço urbano em São José dos Campos - SP. Dissertação (Mestrado em Sensoriamento Remoto). São José dos Campos: Instituto Nacional de Pesquisas Espaciais, 2002.

IBGE - Instituto Brasileiro de Geografia e Estatística. Recenseamento Geral do Brasil no ano de 2000 (para unidades da federação e municípios). Rio de Janeiro, 2000. lise espacial do IDH intraurbano. Análises mais críticas e aprofundadas dos resultados não estiveram na concepção deste artigo. Sugere-se, portanto, que se façam tais análises em trabalhos futuros, empregando os resultados aqui alcançados ou então que se replique a metodologia proposta em outros municípios, utilizando este trabalho como referência bibliográfica.

ISAAKS, E. H.; SRIVASTAVA, R. M. An introduction to applied geostatistics. New York: Oxford University Press, 1989.

JAKOB, A. A. E. A Krigagem como método de análises de dados demográficos. In: XIII ENCONTRO DA ASSOCIAÇÃ̈O BRASILEIRA DE ESTUDOS POPULACIONAIS. Anais... Ouro Preto, 2002.

OLIVEIRA et al. Espacialização dos Índices de Desenvolvimento Humano - IDH por cartogramas corocromáticos estatísticos. In: COBRAC 2008. Florianópolis: Universidade Federal de Santa Catarina, 2008.

PMV - Prefeitura Municipal de Viçosa. Do café à cidade educadora. Disponível em: <http://www.vicosa.mg.gov. $\mathrm{br} /$ ?area $=$ conteudo\&secao $=19>$. Acesso em: maio 2009.

PNUD. Atlas do Desenvolvimento do Humano no Brasil - 2003. Brasília, 2003.

Atlas do Desenvolvimento do Recife (PE), 2005. Disponível em: <http:// www.pnud.org.br/publicacoes/atlas_recife/ index.php>. Acesso em: nov. 2008.

Programa das Nações Unidas para o Desenvolvimento. Disponível em: <http://www.pnud.org.br/home/>. Acesso em: nov. 2008.

Ranking do IDH Municipal. Disponível em: <http://www.pnud.org.br/atlas/ ranking/IDH-M\%2091\%2000\%20Ranking\%20 decrescente\%20(pelos\%20dados\%20de\%20 2000).htm >. Acesso em: abr. 2009.

RAMOS, F. R. Análise espacial de estruturas intraurbanas: o caso de São Paulo. Disserta- 
ção (Mestrado em Sensoriamento Remoto). São José dos Campos: Instituto Nacional de Pesquisas Espaciais, 2002.

SANTOS, N. T. Estatística Espacial Aplicada. Apostila da pós-graduação em Estatística. Viçosa - MG: UFV, 2008.

SCHULER, A. R. Mapeamento geoestatístico de ensaios de prospecção geotécnica no município do Rio Grande. Monografia (Trabalho de conclusão do curso de Engenharia Civil). Rio Grande: Fundação Universidade Federal do Rio Grande, 2007.

UFV - Universidade Federal de Viçosa.

Notícias diárias. Disponível em: <http:// www.ufv.br/>. Acesso em: jun. 2009.
VICENTE, J. Estudos comparativos de métodos geoestatísticos aplicados em agricultura de precisão. Dissertação (Mestrado em Engenharia Cartográfica). Presidente Prudente: Universidade Paulista "Júlio de Mesquita Filho" - Unesp, 2004.

WONG, D. Aggregation effects in georeferencial data. In: ARLINGHAUS, S. L. Pratical handbook of Spatial Statistics. CRC Press, 1995.

\section{Resumen}

Propuesta metodológica para el cálculo y análisis espacial del IDH intraurbano de Viçosa - MG

El análisis de indicadores socioeconómicos permite una lectura de la realidad capaz de contribuir a la planificación urbana y gestión municipal. El Índice de Desarrollo Humano (IDH) es un importante medidor del nivel de desarrollo de un municipio, por contrastar condiciones de renta, educación y longevidad, sin embargo, no es capaz de manifestar las diferencias sociales dentro del municipio. En este sentido, con el objeto de entender mejor la cuestión socio-espacial urbana, la creación de indicadores locales (como el IDH sectorizado) se convierte en una importante herramienta de análisis. La metodología de cálculo de este índice fue adaptada a los datos del Censo 2000 del IBGE, que se encuentran disponibles agregadamente por sectores censitarios, que constituyen la menor unidad de análisis territorial compuesta por datos censitarios. Con el fin de que se comprenda mejor la distribución y continuidad espacial del IDH, este trabajo propone la aplicación de técnicas de geoestadística vinculadas al geoprocesamiento. Se consigue, por tanto, el análisis de la continuidad espacial del IDH intraurbano, por medio del interpolador geoestadístico de Krigeaje Ordinario. Este proceso permite inferir el comportamiento espacial del desarrollo humano, que posee una variación continua en el espacio. Se resalta que se trata de inferencias no sobre los valores locales del IDH, sino sobre las tendencias de la variabilidad del indicador. Los resultados se mostraron satisfactorios, visto que es posible hacer una lectura espacial del desarrollo humano intraurbano, a partir de los datos secundarios presentados por el censo.

Palabras-clave: Índice de Desarrollo Humano (IDH). Sectores censitarios. Estadística espacial. Krigeaje.

\section{Abstract \\ Methodological proposal for spatial calculation and analysis of the intra-urban HDI of Viçosa, Brazil}

Analyses of socioeconomic indicators allow a way to read reality that can generate information for urban planning and municipal management. The Human Development Index (HDI) is an important measure of the level of development in a municipality, as it calculates income, education 
and longevity. However, it is unable to indicate social differences within a municipality. To better understand the question of urban socio-spatiality, the construction of local indicators (such as sectorial HDIs) becomes an important analytic tool. The methodology for calculating this index was adapted to data from the Brazilian Census of 2000 , which is arranged in an aggregated way per census sector, which constitute the smallest unit of territorial analysis based on census data. In order to better understand the distribution and spatial continuity of the intra-urban HDI, this article proposes that geo-statistic techniques be applied in conjunction with geo-processing. In this way, researchers have at hand an analysis of the spatial continuity of an intra-urban HDI by using an ordinary geo-statistic kriging interpolator. It thus becomes possible to infer regarding the spatial behavior of human development, which always shows continuous variation in space. It should be stressed that such inferences refer not to local levels of the HDI but rather to trends in the variability of the indicator. The results are considered satisfactory since a spatial reading of intra-urban human development can be made on the basis of secondary data generated by the census.

Keywords: Human Development Index (HDI). Census sector. Spatial statistics. Krigage.

Recebido para publicação em 01/12/2009

Aceito para publicação em 15/06/2010 